Results From 42 patients started on Guanfacine, 37 (88\%) were boys, girls were $5(11.9 \%), 20$ patients $(47 \%)$ were older than 11 years. Guanfacine was used as a second line in 30 cases $(71 \%)$ and $3 \mathrm{rd}$ line in 8 (19\%), while 4 cases $(9.5 \%)$ in whom stimulant drugs were not suitable were put on Guanfacine as a first line.

The reason for changing the medication to Gaunfacine was; it didn't give desirable effect in $19(45 \%)$ cases, wasn't tolerated in 6 (14\%), weight loss and appetite suppression in 6 (14\%), sleep disturbances in $1(2 \%)$, high blood pressure in 4 (9\%), caused suicidal thoughts and depressive mood in 1 $(2 \%)$, headache and emotional instability in $1(2 \%)$, tics in one case (2\%). Duration of treatment ranged from 2-13 months.

37 cases $(88 \%)$ are continuing Guanfacine while 5 stopped using it, $3(7 \%)$ were trialled for short time and was felt by parents to be ineffective, 1 was lost to follow up, and 1 stopped all medications as symptoms have improved.

Conclusion Guanfacine was well tolerated and beneficial in 38 cases (90\%). In 38 cases (90\%) it was prescribed as per NICE guideline. Only in 4 cases $(10 \%)$ was it prescribed as a first line, these cases in which stimulant drugs were unsuitable were analysed and will be discussed during presentation with the aim of sharing experience and suggesting specific indications for use.

\section{G620 AUTISM AWARENESS IN THE PAEDIATRIC STAFF}

${ }^{1} \mathrm{NL}$ Weerapperuma, ${ }^{2} \mathrm{~K}$ Dayasiri, ${ }^{1} \mathrm{~A}$ Rose. ${ }^{1}$ Department of Community Paediatrics, Oxford University Hospitals, Oxford, UK; ${ }^{2}$ Deparement of Acute Paediatrics, Oxford University Hospitals, Oxford, UK

\subsection{6/archdischild-2020-rcpch.534}

Background Children with autism have needs which are often not visible. When these children admit to hospital, they need accommodations within acute care settings. Awareness of the frontline paediatric staff of these needs and ways to support these children and families, can improve the quality of care provided and make the experience pleasant. This study has assessed the awareness and perceptions about children with autism among a multi-disciplinary group of front-line paediatric staff working in the ambulatory care unit and the paediatrics wards, in a tertiary paediatric hospital.

Methods The study was conducted in acute paediatric wards in September 2019. Randomly selected twenty-nine staff members were interviewed with a structured questionnaire. Demographic profiles of respondents were analysed to identify patterns. Individual responses for questions were analysed qualitatively by thematic content analysis and quantitatively by statistical analysis.

Results Respondents were heterogeneous in disciplines (nurses (14, 48.3\%); health care assistants (8, 27.6\%); play specialists (2); junior doctors (2); registrars (2) and music therapist (1). Eighteen $(62.1 \%)$ believed they were confident in caring for a child with autism. Only one respondent knew how common autism is, while others overestimated (14, 48.3\%); underestimated $(4,13.8 \%)$ or had no idea $(10,34.5 \%)$. Majority knew at least one key feature of autism $(24,82.8 \%)$ and most respondents had mentioned difficulties in social interaction $(12,41.4 \%)$. The majority knew how children with autism would respond when they are upset (26) and what factors can disturb them (28). Most frequently reported supportive action in the acute hospital setting was provision of a quiet room with minimal disturbance $(14,48.3 \%)$. Eight respondents $(27.6 \%)$ were not aware how they can help children with autism.

Conclusion Though the majority of respondents were knowledgeable about presenting features of autism and factors that can upset children with autism, a notable majority was not aware how common the problem is and another significant proportion did not feel they were confident to care for a child with autism. Lack of awareness about autism in the frontline staff in a ward environment reinforces the importance of raising autism awareness in the studied setting.

\section{G621 GROWING PAINS! CAN GPS (GENERAL PAEDIATRICIANS) HELP?}

RM Vardan, VB Pulla, SK Nelapatla. Paediatrics, North Lincolnshire and Goole NHS FT, Scunthorpe, UK

\subsection{6/archdischild-2020-rcpch.535}

As $\mathrm{RCPCH}$ has predicted we are all witnessing the mental health epidemic and National Health Service is struggling to cope with the demand. Physical/organic disease still remains the priority and drains precious resources. CAMHS remains undersourced and overwhelmed. Post code lottery still exists for most part of the country except the large metropolis.

Paediatricians are uniquely placed and trained to help children and families. Challenging behaviour is viewed as somebody else;s problem. Education of parents, schools, health care professional is the need of the hour.

We will explore ways how mental health problem recognition, treatments, sign posting can be a part of holistic care. $\mathrm{MH}$ is the 'other side of the coin'/elephant in the room/ stigma. It has devastating effect not only on the child but the family, society and can cost the nation dearly.

RCPCH in 2017 has submitted to NHS England how mental health should be considered in its long term health plan. RCPpsych and RCGPs are collaborating in this commendable effort at a strategic level.

The situation unfortunately on the shop floor remains unaltered with waiting times getting longer, referals rejected, children excluded from schools and families on the verge breaking down. General Paediatricans we believe can make a real difference with a little help from clinical leads, service providers and commisioners.

\section{G622 WHICH FACTORS AFFECT THE MEDICATION STABILITY OF PATIENTS WITH ADHD THROUGH THE TRANSITIONAL PERIOD FROM PAEDIATRIC TO ADULT CARE?}

${ }^{1} \mathrm{M}$ Edmonds, ${ }^{2} \mathrm{R}$ Gallagher. 'School of Medicine, University of Liverpool, Liverpool, UK; ${ }^{2}$ Consultant Developmental Paediatrician, Alder Hey Children's Hospital, Liverpool, UK

\subsection{6/archdischild-2020-rcpch.536}

Aims It is known that adolescents with a diagnosis of attention deficit hyperactivity disorder (ADHD) are particularly vulnerable at the transitional period from paediatric to adult care. The aim of this study is to determine factors which may 
affect the prescription stability of adolescent patients who live with ADHD.

Methods We conducted a retrospective cohort study investigating 65 adolescents who were receiving prescriptions for ADHD medication. The patients were categorised into two groups, 'stable' and 'unstable', based on prescription changes over a three year period. The groups were then compared based on the medication prescribed, dose of medication, comorbidities, BMI and gender and reasons for prescription changes were noted.

Results The study found a statistically significant correlation between adolescents prescribed Elvanse and prescription changes (OR: $19.63 \mathrm{P} \leq 0.05$ ). Further to this Patients who were receiving an unlicensed dose of Concerta XL were also more likely to have a prescription change (OR: 11.00 $\mathrm{P} \leq 0.05)$. A key finding was the strong association between side effects and instability of prescriptions (OR: 936 $\mathrm{P} \leq 0.0001)$.

Conclusion This study revealed associations between patients prescribed Elvanse and increased changes to their medications. This also applied to those receiving an unlicensed dose of Concerta XL.

\begin{tabular}{ll} 
Abstract G622(P) Table 1 & Reasons for prescription change \\
\hline Reason for prescription change: & Total: \\
\hline Patients choice & 10 \\
Ineffective medication & 42 \\
Weight changes & 2 \\
Side effects & 18 \\
Co-existing conditions & 3 \\
Unrecorded & 9 \\
Total & 83 \\
\hline
\end{tabular}

This study also highlights the common reasons for medication change (table 1) in this transitionary period.

\section{G623 NON PSYCHIATRIC COMORBIDITIES IN ADHD: A SCOPING EXERCISE}

SJ Perera. Paediatric, Southend University Hospital, Westcliff-on-Sea, UK

10.1136/archdischild-2020-rcpch.537

\section{Aims}

- Literature review of comorbidities of Attention Deficit Hyperactivity Disorder (ADHD) with a view to identify publications on non-psychiatric comorbidities.

- Identify the non-psychiatric comorbidities in Paediatric Neurodevelopmental clinic patients with ADHD.

\section{Methods}

- A literature survey was conducted using MEDLINE under the terms ATTENTION DEFICIT HYPERACTIVITY DISORDER, ADHD, COMORBIDITY, CO-OCCURRENCE, MULTIMORBIDITY and DUAL DIAGNOSIS in metaanalysis OR Reviews articles published in English Language from 2013.

- Paediatric in-patient admissions for the age range 4-17 years during a consecutive period of 24 months was analysed to find out what the primary and secondary diagnoses were.
- Light House Child Development centre outpatient's clinic codes for ADHD and behavioural paediatrics were used to identify the cohort of children with a primary or a secondary diagnosis of ADHD to check for emerging comorbidities.

- A single clinician's sample was used for the preliminary survey

Results

- Sixty journal articles met the search criteria. Two articles on obesity, one on developmental motor coordination, five on atopic dermatitis, one on asthma and one on bedwetting met the non-psychiatric comorbidities (table 1).

- 1307 patients were admitted to the paediatric department between 01.01.2017-31.12.2018.one coded for Hyperkinetic disorder as a secondary diagnosis.one had ODD as a primary diagnosis.

- 3472 clinic episodes/patients were identified in neurodevelopment clinics with $\mathrm{ADHD} /$ behaviour problems.

- 40 patients were identified from the single clinician led clinic to have ADHD. And other comorbidities.

One had a dual diagnosis of ADHD and MCAD deficiency.

\begin{tabular}{lllll}
$\begin{array}{l}\text { Abstract G623 } \\
\text { yrs. Mable } 1\end{array}$ & Number of children 40. Age range 7-17 \\
\hline Dsorder & ADHD & $\begin{array}{l}\text { Psychiatric } \\
\text { comorbidity }\end{array}$ & $\begin{array}{l}\text { non Psychiatric } \\
\text { comorbidity }\end{array}$ & Mixed \\
\hline Primary DX & 37 & 3 & 4 & \\
Secondary Dx & 3 & 35 & & 17 \\
TOTAL & 40 & 38 & 4 & 17 \\
\hline
\end{tabular}

Obesity as a diagnosis was coded in none. Mixed group had Learning difficulties in 7 , sleep problems in 10 . The additional diagnoses of Looked after children adopted was recorded but not included as a non-psychiatric or mixed disorder.Management of comorbidities were studied.

Conclusions Non-psychiatric disorders are present in ADHD Children and young people (CYP) but in fewer numbers in this preliminary survey.

A detailed analysis of the outpatient data is ongoing and may shed more light into the prevalence of uncommon comorbidities of ADHD.

Limitations of the study and further recommendations will be discussed.

\section{G624 INCORPORATING COGNITIVE NEUROSCIENCE INTO INFLUENCING THE WIDER PICTURE OF CHILD HEALTH}

N Kamal. Community Paediatrics, George Still Forum, Kingston upon Hull, UK

\subsection{6/archdischild-2020-rcpch.538}

Various statistical data have been used as indices for the national profile of population and child health. Newer social factors have surfaced in the recent times such as aggression and criminalty amongst youth which compel us to include into the equation to reflect on Mental Health profile of the present youth and future community. Aim should be to offer due eminence to Child mental health. 